\title{
Aprender en el aprender a lo largo de la vida
}

\section{Learning bylearning throughout life}

\author{
José Manuel Velasco Toro \\ Universidad Veracruzana/Universidad Pedagógica Veracruzana (México)
}

\section{Resumen}

En el presente ensayo incursionamos en la reflexión del concepto de aprendizaje a partir del conocimiento que está proporcionando la neurociencia y las ciencias de la complejidad, la relevancia que posee el vislumbrarlo desde la perspectiva de aprender en el aprender, comprender, cómo es que aprendemos, la relevancia del aprendizaje a lo largo de la vida y lo que implica el hacer educativo en la sociedad del conocimiento. Aproximaciones que buscan aportar elementos para un diálogo en torno al principio de aprender a lo largo de la vida, acción que conlleva aprender en el hacer para desarrollar el ser en la plasticidad del continuo aprendizaje.

Palabras clave: Aprendizaje; aprender en el aprender; a lo largo de la vida; emoción; curiosidad.

\begin{abstract}
In the present essay we delve into the reflection of the concept of learning from the knowledge provided by neuroscience and the sciences of complexity, it's relevance from the perspective of learning by learning, understanding how we learn, the relevance of lifelong learning and what it implies in the educacional doing in the social knowledge. Approaches that seek to provide elements for a dialogue around the principle of learning throughout life, action that involves the learning process for developing the being in the plasticity of continuous learning.Keywords: Learning; learning bylearning; throughout life; emotion; curiosity.
\end{abstract}

\section{PROEMIO}

Estamos en el transcurso de la segunda década del siglo XXI. Un lapso no muy alejado del siglo XX, centuria en la que sentíamos que los ritmos de la historia permitía sondear el pasado en ilusión experiencial del presente para planificar el futuro. La modernidad la creíamos "sólida" y la dinámica social consistente (Bauman, 2007). Hoy, el signo es el cambio acelerado y la incertidumbre se muestra constante, rasgo que caracteriza la transición de épocas en el proceso civilizatorio que continuamente se moderniza. Estamos ante un Mundo donde "conocer es constituir" (Skolimoski, 2016), en el que continuamente tenemos que estar aclarando nuestra mente para comprender la acelerada hipermodernidad, como lo nomina Lipovestsky y Serroy (2010).

Éste suceder histórico que nos trasladó del lento movimiento de certidumbre social a la constante marejada de incertidumbre, sucedió en apenas cincuenta años, lapso que comprende prácticamente la segunda mitad del siglo XX e involucró a dos 
generaciones. A diferencia de más de dieciséis generaciones que vivieron, no sin acontecimientos traumáticos, el cambio de la Modernidad al Mundo Contemporáneo, cuyo ritmo de tiempo histórico dio origen a una "visión científica del mundo" que fue difundida mediante la escuela pública, institución capaz de influir en la mente y cultura del pueblo mediante el ejercicio de la enseñanza y el aprendizaje. Algoritmo cuyas bases epistémicas y ontológicas se tradujeron en prácticas pedagógicas que conformaron una cosmovisión de la escolaridad fundada en la reducción del individuo a la relación dual de profesor-alumno. Linealidad cuya causa radica en la persona que trasmite y el efecto en la persona que toma lo que le es trasmitido.

En el presente ensayo buscamos sentar premisas para trascender la visión implicada en el binomio enseñanza-aprendizaje. Incursionamos en el concepto de aprendizaje explicado desde el ámbito de la neurociencia, la importancia de aprender en el aprender para comprender, cómo es que aprendemos y la relevancia del aprendizaje a lo largo y para la vida, aspecto con el cual cerramos el texto, pero no la reflexión.

\section{APRENDIZAJE, LA DEFINICIÓN CLÁSICA}

Para comprender lo enunciado es necesario explicar, aunque sea en brevedad, el concepto de aprender que se define en el repertorio contenidos en el diccionario. El Real Diccionario de la Lengua Española señala que el vocablo aprender significa: "Adquirir el conocimiento de algo por medio del estudio o de la experiencia", "Tomar algo en la memoria" o "Enseñar, trasmitir unos conocimientos". En el repertorio del Diccionario Actual de la Lengua Moderna, se define: "Adquirir el conocimiento de alguna cosa por medio del estudio o de la experiencia". En éste mismo diccionario se precisa que el aprendizaje es "el proceso mediante el cual el hombre adquiere y asume la cultura del entorno en el que vive". Por su parte, el Diccionario de la Lengua Española explica que aprendizaje significa: "Adquisición para la práctica de una conducta duradera".

Si bien las definiciones anotadas tienen ligeras diferencias semánticas, todas apelan al hecho común de considerar el aprendizaje como una acción que proviene del exterior del sujeto, que se memoriza y establece su conducta (Velasco, 2015). Dos elementos queremos resaltar de los axiomas apuntados:

Primero, el aprendizaje se reduce a la acción mediante la cual la persona adquiere conocimiento de lo externo; en este sentido, se concibe como apropiación por transferencia. 
Segundo, aprender es adquirir una conducta duradera; es decir, adaptarse a la cultura del entorno.

El aprendizaje, se pensó, ocurría como la operación de transferencia de información que proviene del exterior, por tanto era necesaria su enseñanza que debía proceder de parte de quien sabe hacia el receptor de ese saber; esto es, se concibió centrada en el profesor quien es el que realiza la acción de "comunicación de conocimientos, habilidades, ideas, experiencias a una persona que no las tiene para que las comprenda y haga uso de ella" (www.WordReference.com). Desde esta perspectiva paradigmática, el algoritmo enseñanza-aprendizaje se explicó como el proceso mediante el cual se adquiere información proveniente del exterior que es mostrada y direccionada (enseñada) para que la persona adquiera (aprendizaje) la cultura que le permita asumir la conducta social del entorno (adaptación social). Lógica en la que el alumno carece de autonomía para decidir qué, cómo, cuándo y dónde realiza el aprendizaje.

Visión paradigmática que fue funcional hasta la década de los años ochenta del siglo XX, temporalidad en la que aún se mantenía una cierta certeza en la relación economía-sociedad. Lo aprendido en el sistema escolar proporcionaba la instrucción necesaria para incursionar y desarrollarse en el ámbito laboral y cultural. Se vivía un presente formador inmerso en un pasado de referencia cuyo peso ideológico se percibía funcional (arcaísmo persistente) y necesario para la reproducción social y laboral. Fenómeno conocido como "fijación funcional" (Konnikova, 2014, p. 129), ya que se tiende a ver las relaciones que se presentan como situaciones asignadas y con función concreta.

Lo cierto es que la organización escolar fundada en el paradigma enseñanzaaprendizaje, donde el alumno no actúa sino reacciona, se muestra retrograda ante la dinámica del cambio derivado de la Sociedad del Conocimiento (SC) que exige aprender en el hacer con autonomía a lo largo de la vida, cultivar la imaginación para mantener la capacidad de asombro y saber asumir la incertidumbre con creatividad. Dicho desde otra perspectiva: el conocimiento es un factor de valor y por tanto componente de orden económico y social que está en constante cambio, realidad que en el contexto laboral impone a las personas la necesidad de su permanente actualización gnoseológica, lo que es posible con una educación que cultive la relación aprendizaje-conocimiento en un ambiente humanista de democracia cognitiva que haga germinar en la persona la habilidad intelectual de aprender en el aprender a lo largo de la vida, la habilidad operativa que entreteje lo aprendido con experiencia empírica y la habilidad perceptiva para reconocer y 
comprender lo multidimensional del mundo. De ahí que sea vital trascender hacia el paradigma de aprender en el aprender, donde la preposición en significa el momento y manera en que ocurre el aprender. No es el fin de una acción o destino indicado en la preposición para, ni la constante de $a$, sino estar en el tiempo en que ocurre el hacer para ser, principio de aprendencia que propugna aprender en el hacer para desarrollar el ser en la plasticidad del continuo aprendizaje (Velasco, Peredo, Fuentes, González y López, 2016, p. 76).

\section{CAMBIO Y FUTURO}

A partir de la segunda mitad del siglo XX se aceleró el avance de la ciencia y la técnica, proporcionando conocimientos y tecnologías que están revolucionando nuestro saber en todos los ámbitos de la vida y son factor de cambio en la dinámica social. Biología, Ecología, Cosmología, Física Cuántica, Bioinformática, Nanotecnología, Medicina y demás campos científicos que constantemente nos proporcionan sorpresas sobre el Cosmos, la materia y la energía, el mundo del espacio atómico o sobre la biótica de los microorganismos, la gestión computacional, el manejo nanométrico de la materia o los pasos agigantados realizados por la Inteligencia Artificial (IA) aplicada a los métodos de automatización y auto organización de sistemas; pero sobre todo, cómo es que ocurre el aprendizaje en el operar de nuestro cerebro y nuestra corporeidad, proceso estudiado por la Neurociencia que está entretejiendo lazos con la educación dando origen a la Neuroeducación.

Así tenemos que la biología, física cuántica, sistemas informáticos y otras ciencias en su relación transversal, muestran que la vida no es secuenciación lineal como lo pensamos durante mucho tiempo, sino que ésta se crea y recrea mediante un sistema en red que es dinámico en el entretejido de su función en red y abierto ante los procesos emergentes (Delgado, 2009; Margulis y Sagan, 1996; Maturana y Varela, 2003). En esta dinámica el conocer está en la base de la vida por lo que todo organismo vivo aprende en interacción cognitiva con su entorno. Capacidad que radica en la autoorganización para interaccionar en el medio vivido, conocerlo y crear condiciones que le permite co-emerger al mundo (Luisi, 2010; Luhmann, 1998). En este orden, el conocimiento científico, social y humanístico de hoy nos muestra que la existencia ocurre en un mundo plural cuyo signo es la diversidad, donde la vida es permanente interconectividad que permite establecer conexiones y nuevas relaciones dinámicas (Ohlenschläger, 2009). 
Estamos acostumbrado a concebir la educación escolar como la práctica de aprender derivada del enseñar. Este modelo funcionó mientras el mundo bajo el cual fue ideado mantuvo su equilibrio estructural de certeza al no existir disonancia cognitiva entre lo aprendido y lo reproducido, a la vez de ser utilitario en el orden laboral. Sin embargo, ese mundo de certeza ha cambiado. La dinámica de la SC subsume a la sociedad en un estado de constante cambio social que nos enfrenta a la imperiosa necesidad de aprender permanentemente, condición requerida para afrontar y superar la incertidumbre en la que las condiciones presentes no pueden determinarse simultáneamente. Realidad donde el aprendizaje adquiere cualidad de engrama con la dinámica económica y la mejora productiva de la sociedad (Stiglitz y Greenwald, 2015).

Por ende, el reto educativo es promover la actitud y aptitud para aprender en el aprender a lo largo de la vida que reside en la dialógica de aprender para conocer y conocer para hacer. En esta dialógica aprendizaje-conocimiento se estimula la emergencia de nuevo conocimiento en el que germina un nuevo pensamiento, condición necesaria para que se cree un ambiente donde la creatividad sea acción gestora del descubrir, comprender, anticipar y resolver con presteza bajo circunstancias de cambio constante.

\section{IMPORTANCIA DEL APRENDIZAJE}

Señalamos que el rasgo esencial de la SC radica en los cambios derivados del avance en el conocimiento científico y técnico que impacta, directa e indirectamente, en la dinámica económica, social, cultural, laboral y educativa. La aplicación del saber constituye un factor de valor que relaciona todos los ámbitos de la organización social e implica directamente a la educación, lo que en el contexto productivolaboral impele a las personas a estar inmersas en el fluir del permanente aprender. Realidad a la que tiene que responder la educación escolar para cultivar aprendientes inmersos en el proceso activo de estar aprendiendo, sepan ubicar información para generar conocimiento, identifiquen cómo es dable aplicar el conocimiento para el hacer, sean consciente de cómo en el hacer se aprende a movilizar las habilidades intelectuales, operativas y perceptivas que permiten continuar en el ejercicio de aprender a lo largo de la vida, siempre en relación íntima con el cultivo esencial del hacer ético social. 
Desde la última década del siglo XX (CCE, 2001) se viene insistiendo en la importancia del aprendizaje a lo largo de la vida y saber aprender en el aprender desde temprana edad, base de preparación imprescindible para navegar en la totalidad de la vida y en la conectividad social. Realidad derivada de la "creación, acumulación y sin duda también de depreciación del conocimiento" (David y Foray, 2002, p. 1). Lo que crea un entorno donde la novedad es consustancial a la dinámica social y económica que empuja, ante el riesgo de la exclusión, a sumergirnos en la corriente del aprendizaje para superar el margen de ignorancia entendida como el no saber. La aptitud laboral del futuro requiere de habilidades intelectuales y operativas que permitan a la persona apropiarse, generar y aplicar conocimiento, lo que exige un perfil escolar muy diferente al formado por el sistema escolar que nació con la Revolución Industrial (Stiglitz y Greenwald, 2015).

Ante esta vorágine la dimensión educativa constituye factor esencial de cambio social, pues en ella radica la posibilidad para que se cultive la aptitud y actitud de aprender en el aprender a lo largo de la vida con imaginación propositiva, espíritu de solidaridad en el disfrute social, cultivadora de su ecología cognitiva y consciente de su trascendencia creativa, aún bajo el embate enajenador de la SC. Por ello es fundamental que la educación cultive mentes flexibles y curiosas que "puedan modificarse rápidamente, de acuerdo con los datos que surgen de su intorno y entorno", aptitud de amplia comunicación para saber procrear conocimiento en la resolución de problemas (Marcelo, 2001, p. 541).

\section{APRENDER ES CONOCER}

Hemos mencionado que el avance en el conocimiento sobre la organización de la vida ha demostrado que aprender es un proceso inherente a la vida misma. En este sentido, aprender implica el acto de conocer como acción efectiva y operacional del ser vivo que se adapta a su medio ambiente en el dominio de su existencia (Maturana y Varela, 2003, p. 15). En el ámbito humano aprender también implica sobrevivir, habilidad que se cultiva mediante la educación, proceso que envuelve lo histórico social de nuestra cultura, tanto en lo endógeno de las personas como en la manera del ser social de la cultura vivida. Entonces tenemos que el aprendizaje permite conocer el dominio de la existencia. Esto es en el hacer, que en el caso humano es un proceso biológico innato al mismo tiempo que es un proceso social culturalmente creado. Al observar se percibe, al percibir se comprende y al comprender se aprende, lo que deriva en un cambio de conducta que por ser operacional se eleva a carácter histórico en la persona y desarrolla su Ser. 
Al aprender se pasa de una situación menos efectiva a una acción efectiva en el operar del entorno social vivido, proceso que entreteje emoción y razón movilizando nuestra habilidad intelectual para ser en el hacer. Esta experiencia cognitiva procrea la reorganización de la percepción del entorno que modifica, sutil o profundamente, la cualidad de comportamiento adaptativo de la persona. Al aprender se pone en movimiento la emoción que se conjuga con la razón, la sensibilidad perceptiva y el sentido operativo en conjunción con la espiritualidad (capacidad emocional, intelectual y ética de ser cada día mejor) nodalmente relacionada con la aptitud cognitiva del aprendiente.

En este orden de ideas, el aprendizaje es creativo, sucede en la autonomía del aprendiente y provoca un accionar efectivo que incide en el sentido y hacer de la vida social. Pero también es creativo porque desarrolla en el aprendiente la habilidad de aprender en el aprender, habilidad necesaria en la SC cuyo signo, insistimos, son los rápidos cambios y la constante incertidumbre.

Maturana y Varela (2003), Mora (2008, 2013), Jensen (2004), Luisi (2010) y muchos científicos preocupados por el aprendizaje, coinciden que el aprendizaje es conocer en el existir, donde al vivir se conoce y el acto de conocer, explícita o implícitamente, motiva a un cambio de acción en el entorno vivido. Echeverría explica este proceso contundente cuando dice: "El aprendizaje es aquella acción que nos conduce a un cambio de la acción". Por tanto, el propósito de aprender es "llegar a hacer lo que antes no hacíamos y, muchas veces, lo que antes no podíamos hacer". (Echeverría, 2012, p. 39). Al conocer aprendemos, al aprender conocemos lo que hacemos y comprendemos nuestra capacidad de observación y acción, relación que comunicamos mediante el lenguaje en la cooperación social al crear, recrear y transformar la cultura (Harari, 2014).

Esta acción efectiva de respuesta y adaptación en interacción recurrente con el medio social y cultural del entorno, es acto de consciencia que se hace presente mediante el lenguaje. Hecho social fundamental a través del cual expresamos nuestros pensamientos y en el que ocurre el aprender, porque es en el lenguaje que el ser humano establece la coordinación recurrente de conductas consensuales en interacción desde y con la emoción, lo que permite aprender y comunicar lo aprendido al establecer un accionar consensual. Ese accionar comunicativo de coordinaciones conductuales consensuales, Humberto Maturana (2004) lo llama "lenguajear"; en tanto Noah Harari (2014) se refiere a él como "chismorreo". Dos metáforas que hablan de la comunicación verbal como esencia del accionar social y del aprendizaje. 
Lenguajear o chismorrear, independientemente de la metáfora conceptual que usemos, lo trascendental es que mediante el lenguaje nos relacionamos socialmente, comunicamos emociones e información, explicamos sucesos, elaboramos abstracciones conceptuales que llamamos reflexión. Pensamos el entorno que percibimos y en cual interactuamos; experimentamos nuevas formas de conocer para revelar y transformar la realidad; predecimos al extrapolar secuelas derivadas de la experiencia y proyectamos lo imaginado en búsqueda de un futuro (Velasco, 2015; Echeverría, 2012).

En esta historicidad es donde emoción y razón se trenzan con la memoria, la que al consolidarse nos permite hacer lo que se aprendió a hacer. El recuerdo nos da certeza y sentido de control porque nos ubica en el pasado, de ahí que el ser humano sea un ser histórico al que le cuesta desaprender para reaprender. Paradoja del aprendizaje que crea la ilusión opuesta al sentido del cambio transformacional de la persona en el ser social, cuando es el mismo acoplamiento histórico el que activa nuestra curiosidad al abrir la consciencia hacia la imaginación del futuro y a la aspiración de experimentarnos como constructores de lo por venir (Velasco, 2015).

\section{RAZÓN CON EMOCIÓN}

No hay duda de que aprendemos a lo largo de la vida. Saber derivado del conocer más sobre cómo funciona nuestro cerebro, cómo es qué ocurre el aprendizaje y cómo nos influye el entorno en el que se convive. Este saber es vital para incentivar dinámicas mediadoras que transformen los ambientes educativos para que en ellos fluya la acción pedagógica que cultive el aprender en el aprender para hacer en el conocer del ser. Propensión humana que en la dialógica de hacer para ser y ser para hacer, impulsa cambios cognitivos en la persona que aprende, lo que a su vez acciona actitudes emocionales que van más allá de la simple adquisición de diferentes repertorios de operación, sobre todo porque al modificar los presupuestos desde los cuales se actúa, se da una ruptura interior en el aprendiente y la posibilidad de un salto cualitativo en el ser de la persona (Echeverría, 2012, p. 48).

De ahí la importancia de propiciar ambientes de aprendizaje mediados en los que se favorezca el emocionar en la reflexión para promover el germinar de la habilidad intelectual de aprender en el aprender, lo que a su vez impulsa la habilidad operativa para el aprendizaje permanente a lo largo de la vida. Un ambiente positivo incentiva la interacción emocional de los aprendientes y procrea el deseo de aprender. Proceso progresivo que requiere para su consolidación de la continuidad del aprendizaje 
mismo. La neurociencia ha demostrado que el aprendizaje permanente a lo largo de la vida mantiene activa la curiosidad, habilidad perceptiva que es esencial para propiciar la atención de algo o sobre algo, lo que invariablemente incide en el actuar de la persona, que consciente o inconscientemente adquiere una nueva manera de observar y actuar (Maturana y Varela, 2003; Jensen, 2004; Mora, 2008).

¿Por qué aprender es actuar en el hacer? Francisco Mora explica cómo es que todo proceso cognitivo es consecuencia de la activación de los procesos emocionales que unen sensación con acción, emoción con razón. "Binomio indisoluble", nos dice, porque al percibir captamos señales que proceden del medio que nos rodea activándose nuestro inconsciente emocional que al procesar la información que se recibe activa el proceso cognitivo del razonamiento. Percibir es, entonces, "captar y procesar información" que une la "sensación con la acción" (Mora, 2013, p. 44). Al percibir reaccionamos ante lo "concreto sensorial" de manera inconsciente para de inmediato actuar con la razón al dar respuesta consciente al estímulo sensorial percibido. En este sentido, la acción es la captación del estímulo al que sigue el procesamiento cognitivo de la información en que radica el hacer que conduce al aprender.

Al movilizarse nuestros sentidos por la reacción emocional que nos provoca, se moviliza nuestra sensibilidad perceptiva que a su vez moviliza la razón que nos permite examinar el entorno que nos rodea, sea cual sea. Percibimos y accionamos inconscientemente, lo que acto seguido conduce al hacer consciente cuando se contextualiza la información que se recibe y permite saber cómo proceder. En ese momento dirigimos la atención a lo que se hace y movilizamos nuestra emocionalidad con actitud efectiva al relacionar la experiencia histórica operacional y cognitiva con lo nuevo que se percibe, situación que procrea la conciliación o transformación de la operación conductual en el entorno vivido. Cuando se obtienen resultados efectivos se aprende (lo cual puede darse como proceso implícito o explicito) porque median procesos de convergencia que reorganizan sentimientos y comprensión del mundo, lo que modifica, sutil o profundamente, nuestro ser.

Actuar y hacer es totalidad en el aprender. Condición, que en el ejercicio de lo aprendido, conlleva cambio cognitivo porque en el hacer se consolida lo aprendido y permite la comprensión de lo nuevo, lo cual ocurre en el actuar de la autonomía de la persona. De ahí se sostiene que aprender en el aprender es un proceso recursivo donde converge emoción y razón, relación que abre las ventanas de la curiosidad e incentiva a la mente para mirar hacia un horizonte cognitivo en forma dinámica. Mediación convergente que es esencial para percibir situaciones, esta- 
blecer relaciones, interactuar con el entorno, comprender la complejidad, perseguir al conocimiento, saber para resolver al mismo tiempo que someter a interrogación el saber. Al ocurrir esto en el aprender se procrea cambio cognitivo en el emocionar que permite la recursión en el aprender al conocer, en especial cuando se pasa de pensar cómo son las cosas al comprender cómo ocurre la interacción entre una relación y otra. Rasgo esencial que determina el curso del germinar de la persona aprendiente y corresponde "a la propensión natural del ser humano a adaptarse (no a someterse) y a re-crear su realidad" (López de Maturana, 2010, p. 45).

Trama de relaciones que en todo proceso de aprendizaje entreteje emoción y razón, percepción y cognición, operatividad e intelección que sincroniza el aprender con el conocer y al aprender se transforma, sutil o profundamente, la capacidad de acción y observación, lo que altera la actitud del aprendiente ante el entorno social particular de la existencia (Maturana, 2004; Echeverría, 2012; Mora, 2008). Por eso es que el aprendizaje transforma, sobre todo cuando el aprendiente se observa a sí mismo a la par de observar el entorno, desde y en la intersubjetividad de la convivencia histórica y social. Suceso que establece, a su vez, relaciones posibles de efectividad cognitiva y pasión emocional, lo que da sentido a la acción de aprender para hacer en la vida, pues articula el pragmatismo instrumental de la acción en el hacer y la capacidad creativa del ser en el saber.

\section{APRENDIZAJE A LO LARGO Y PARA LA VIDA}

Hemos resaltado que aprender es dialógica en el conocer para actuar en el hacer, proceso que en la autonomía de la persona abre la posibilidad de comprender lo nuevo. Al actuar prestamos atención porque entramos en contacto perceptual con el mundo, momento en que aplicamos el sentido común al examinar las condiciones existentes para en el hacer razonar sobre las relaciones posibles y probables del entorno, lo que propicia el aprender en el logro de un conocimiento. Interacción que nos conduce hacia un nuevo aprendizaje que, explícita o implícitamente, implica la posibilidad de desaprender algo previamente aprendido al reaprender o aprender algo nuevo. Es germinar la destreza de saber cómo se aprende, cultivar el reconocimiento mismo del proceso de aprendizaje, ejercitar la consciencia de la propia manera en que se aprende, identificar el conocimiento adquirido y reaprender del propio aprender para aplicar el saber en la continuidad del aprender. Bajo esta óptica, propone Puebla Wuth, el acto educativo debe orientarse hacia el cultivo del aprendizaje autónomo "para desarrollar en las personas un conoci- 
miento metacognitivo de su propio acto de aprender y de los procesos de control metacognitivos en sí, que sean necesarios para sistematizar y hacer eficiente el aprendizaje" (Puebla, 2009, p. 1).

Conocer nuestro pensamiento es fundamental para cultivar la habilidad de aprender en el aprender a lo largo de la vida, movimiento que nos permite saber qué hacer, por qué, cómo, cuándo y para qué se hacen las cosas. Este proceso ocurre en la autonomía de la persona que lo hace consciente mediante el lenguaje, auto referencia que entreteje la habilidad intelectual al procesar lo aprendido y la habilidad operativa que incorpora lo aprendido como vivencia del aprendiente, consolidándola en la memoria. Al aprender se pone en movimiento la emocionalidad y la razón del aprendiente, dupla inseparable que involucra motivación, atención, acoplamiento histórico estructural y corporalidad, relación que es acción en el proceso de aprender para conocer, y en el fluir dinamiza la actitud de compromiso del propio aprendiente desde y en su autonomía que está en interacción lingüística con el entorno social vivido.

Al cultivar la habilidad perceptiva, cuyo proceso no es representacional sino dinámico, el fluir del aprender en el aprender incentiva la curiosidad, sobre todo cuando la novedad se hace presente, momento en que se entra en atención para ubicar el estímulo y procesar la información pertinente y relacional que se recibe. Lo que en simultaneidad examina el contexto general de una situación a la par de reconocer objetos, personas, datos, orden cognitivo y emocional que integra la información al elevarla a la cualidad de conocimiento, en sí y para sí en la persona dentro el contexto social y cultural en el que se realiza.

Cuando se consolida lo aprendido en la memoria del aprendiente, hay transformación en su percepción y operatividad conductual, lo que abre las puertas a la posibilidad de desaprender para aprender al pasar de una situación poco eficiente a otra más eficiente para operar en el entorno vivencial propio (en el ser) y la experiencia vivencial social (en el hacer). Este movimiento cognitivo no es secuencial, sino nodal. Su dinámica dialógica se da en el aprender cuando en el aprender se genera conocimiento pertinente a lo largo de la vida y para la vida. En esto no hay un paso a paso, sino un hacer que trenza, en continuo recursivo, el impulso de comprender en qué radica el aprendizaje, cómo aprendo en relación con el contexto vivencial, cómo identifico el problema o aquello sobre lo cual requiero aprender para generar conocimiento relacional, cómo ubico los datos que me permitan elaborar la información abstracta y concreta vinculada con lo que quiero o necesito saber, cómo evalúo mi paso al desaprender para aprender algo nuevo 
y cómo aplico lo aprendido en el entorno y contexto dado. Toda este fluir, con el tiempo y con práctica, me muestra cómo pienso porque obliga a pensar con profundidad durante toda la vida.

Empero, para arribar a ello es preciso saber poner atención a aquello que tiene que ser observado en el entorno que me afecta. Acto de percepción consciente que permite a nuestro pensamiento, en un primer plano, preguntarnos acerca del estímulo recibido y el problema a atender para, en un segundo momento, establecer nuestro objetivo atencional y abordarlo para conocerlo. Habilidad perceptiva que consiste en atender qué, cómo observar y cómo pensamos lo que hacemos hacia lo percibido. En otras palabras, al "observar con plena consciencia que es lo que percibimos - y cómo lo percibimos - formará la base de las deducciones futuras que podamos hacer. Significa ver la imagen completa fijándonos en los detalles importantes y saber contextualizar esos detalles en un marco más general de pensamiento" (Konnikova, 2014, p. 78).

Por experiencia empírica sabemos que cuando atendemos lo percibido reaccionamos desde nuestra emoción motivados por la fuente de estímulo significativa. Tras esa fracción de tiempo emocional, de inmediato se moviliza nuestra habilidad intelectual mediante la cual buscamos identificar para procesar la información sensorial, la que al integrarla procrea el proceso de creación cognitiva experiencial que es "única y personal (un acto unificado y privado)" de "agrupamiento funcional" que al ser consciente se presenta "único en el tiempo y en el espacio", implicación subjetiva porque es "única y personal" (Mora, 2008, pp. 186-187). En la autonomía de este proceso de "agrupamiento funcional", es donde generalmente integramos los conocimientos previamente adquiridos que nos permiten comparar lo conocido con la emergencia de lo nuevo que se nos presenta, porque al momento de dirigir nuestra atención hacia aquello que requiere de nuestra observación, ocurre la interrelación funcional de los "niveles neurales" que en nuestro cerebro organizan, procesan y analizan la información elevándola, en cuestión de milisegundos, a experiencia consciente.

También sabemos que la atención se fija por cortos intervalos de tiempo y que es tan volátil como el instante del presente. De ahí que es necesario reactivarla mediante la motivación emocional, procurando para ello pensar sobre nuestro objetivo, el interés que tenemos y el aprendizaje que obtendremos al conocer. Sin embargo, en este momento debemos estar atentos a separar nuestras creencias de los hechos y comprender que toda observación implica dialógica entre lo que observamos y cómo lo observamos, es decir, entre el antes y después de nuestra 
intervención. Singularidad que, en palabras llanas, es integral y nodal, de ninguna manera parcializada o secuencial, pues básicamente el sistema sensorial actúa en red desde la respuesta emocional con la razón y el sistema cognitivo que pregunta, procesa y busca respuesta integrando la información que se expresa en conocimiento unificado.

Pero ¿por qué hablamos de aprendizaje a lo largo de la vida? Pecando de simplificación y brevedad, diremos que dos son los elementos esenciales que están implicados en ello: el biológico y el social. El primero refiere a la plasticidad cerebral que es la cualidad que tiene nuestro sistema nervioso para cambiar su estructura y establecer conexiones neuronales en interacción con el medio ambiente, sobre todo cuando está inmerso en un nuevo aprendizaje o experiencia distinta, lo que permite aprender a lo largo de la vida a todo ser humano (OCDE-CERI. (2004). El segundo se ubica en la dinámica de cambio productivo derivado de la constante renovación del saber científico y tecnológico, fruto de la SC, cuyo fluir sumerge en la transformación laboral y social, realidad que obliga a la permanente actualización gnoseológica. De hecho (iy he aquí la paradoja!), conocer que el cerebro aprende a lo largo de la vida y la necesidad de estar en constante aprendizaje para la vida, se corresponden en un mundo que está en acelerado cambio, ante el cual hay que afrontar situaciones emergentes bajo situaciones de incertidumbre. Sobre todo, porque ahora se demanda un conocimiento que incluya "realidades sobre objetos, personas y situaciones del mundo externo", así como habilidades intelectuales que giren "alrededor de objetivos, opciones de acción, predicciones de resultados futuros y planes para la puesta en práctica de objetivos a escala de tiempos variadas" (Damasio, 2013, p. 131).

La plasticidad del cerebro, nos dicen de manera sencilla Blakemore y Frith, es "la capacidad del sistema nervioso para adaptarse continuamente a circunstancias cambiantes" (2007, p. 183). Precisemos un poco. Hacia la década de los años noventa del siglo XX (bautizada como la década del cerebro), se echó abajo la idea (la que aún persiste en muchos conjuntos sociales) de que el cerebro humano envejecía irremediablemente a partir de los cuarenta años y de que el cerebro adulto ya no cambiaba, creencia que sustentó la falsa apreciación de que a partir de ese momento se era incapaz de seguir aprendiendo (justificación por la cual una persona que tenía cincuenta años o más edad se enfrentaba al rechazo laboral y académico). También se tenía profundamente arraigada la presunción de que la estructura cerebral sólo se desarrollaba durante la infancia y al llegar a la edad adulta ese proceso se frenaba, por lo que el rango de aprendizaje era mínimo o 
prácticamente nulo. Sin embargo, ¿qué es lo que hoy se conoce a la luz del avance de la neurociencia? Lo que sabemos es totalmente contrario a las dos ideas arriba descritas.

En primer plano, el cerebro posee una plasticidad que le permite ajustarse a situaciones cambiantes a lo largo de la vida cuando requiere adquirir nueva información del entorno vivido, desde la infancia hasta la vejez. Si bien con la edad disminuye la plasticidad y rapidez con la que se aprende, ello no es sinónimo de imposibilidad en el aprender, pues en la edad adulta la plasticidad no desaparece y el aprendizaje nuevo incorpora la experiencia haciéndolo más reflexivo y profundo. El aprendizaje permanente, nuevo y continuado que exige la vida (sobre todo cuando se está en un entorno cambiante y complejo), genera cambios en nuestro cerebro, cuya relación de mayor o menor dinámica está dada por el ejercicio mental que realicemos ante las situaciones del entorno. "Lo que no se usa se pierde", nos dice de manera llana Blakemore y Frith (2007, p. 184). Metáfora que refiere a una realidad insoslayable. Para que el cerebro se mantenga germinal en su plasticidad, tiene que estar inmerso en la permanente adquisición de nueva información que le permite adquirir nuevas destrezas y habilidades intelectuales, operativas y perceptivas. Habilidades que tiene que poner en práctica para poder consolidarlas, es decir, conservarlas y cultivarlas.

¿Cómo sucede esto? Cuando se realiza algo desconocido, como adquirir nueva información relacionada con aquello que interesa e incide en nuestra cotidianeidad, aprender otra lengua, sumergirnos en la lectura de algo novedoso o requerido, como también realizar una operación mecánica que implica atención para comprender y aprender, de inmediato nuestro cerebro inicia un cambio en la conexión neural que, de mantenerse la actividad de aprendizaje, desemboca en un cambio físico al formar más redes neuronales que refuerzan las más activas y se debilitan aquellas que son menos activas (Blakemorey Frith, 2007; OCDE-CERI, 2004.). Por ello, cuando existe un ambiente complejo que medie el aprendizaje a largo plazo, este conduce a modificaciones profundas que abren la posibilidad de adquirir nuevas destrezas y modificar nuestra actitud conductual. En cambio, un ambiente limitado que no propicia condiciones para generar nuevos aprendizajes a largo plazo desemboca en una poda de redes neuronales, lo que reduce el horizonte en el cultivo de nuevas habilidades, aunque no coarta la posibilidad de aprender. La plasticidad permite adaptarnos a condiciones cambiantes y ocurre a lo largo de toda la vida de la persona. Sin embargo, existe una paradoja. Al fortalecerse las redes neuronales como resultado de la repetición de una actividad, sea física o intelectual, el aprendizaje 
adquirido tiende a convertirse en habito que repetimos una y otra vez (Carr, 2013, pp. 41-42). De ahí el problema de aprender a desaprender de manera consciente a lo largo de la vida.

En segundo plano, la actual dinámica económica, social, cultural, educativa, ética y laboral de la SC que es consustancial a los constantes y novedosos cambios en el orden de la ciencia, la tecnología, la condición organizacional, el intercambio informacional, la movilidad laboral, la innovación como inquebrantable impulso hacia lo nuevo, la dinámica del pensamiento nómada cuyo rasgo es crear vocaciones inéditas y el entrelazamiento de actividades imbuidas en diversas dimensiones del saber, constituyen nodos relacionales que subsumen a la persona en la inevitable necesidad de aprender en el aprender a lo largo de la etapa vital, condición necesaria para mantener presencia en la turbulencia social y laboral. En este orden de ideas, el aprendizaje a lo largo de la vida es condición, sine cuan non, de sobrevivencia desde la perspectiva individual, colectiva, social y laboral. Realidad insoslayable que desde inicio del siglo XXI se ubicó como rasgo de esta época, cuya constante es la permanente emergencia de conocimientos que obligan a estar, al día a día, ante la mengua del mismo conocimiento. Relaciones que inevitablemente conllevan a reorientar la acción educativa hacia la creación de ambientes de aprendizaje donde las personas cultiven habilidades intelectuales, operativas y perceptivas que le permitan crear y reproducir conocimiento, percibir ámbitos de intercambio con posibilidades de recombinación y transposición, comuniquen e interactúen colaborativamente para coproducir, apliquen el uso de tecnologías de información y comunicación, así como saber combinar conocimiento explícito e implícito en lo individual y colectivo (David y Foray, 2002; Lucinnovation, 2008).

Lo anterior implica que la dinámica educativa se movilice en torno al nodo generativo de la relación aprendizaje-conocimiento. Es decir, el aprender en el aprender se sitúa en la dimensión interactuante de la emoción y la razón de la persona, que en el entorno vivido establece relación con el conocimiento que al interactuar propicia la emergencia de nuevo conocimiento en el hacer. Ejercicio intelectual que va más allá de la implicación del binomio enseñanza-aprendizaje porque cultiva, en y desde la autonomía de la persona, mutuos y múltiples cambios cognitivos y experienciales en el proceso de aprender para conocer (Assmann, 2002). 


\section{CURIOSIDAD PARA APRENDER}

Hasta aquí hemos intentado explicar cómo aprender en el aprender es la acción que nos conduce hacia la procreación de conocimiento en el hacer y cómo al establecer la relación con el conocer nuestro ser se abre a la posibilidad del cultivo espiritual. Aprender en el hacer reorganiza nuestra visión hermenéutica, pues al conocer se provoca experiencias de aprendizaje cuyo potencial cognitivo reside en la autonomía del aprendiente. Esta dinámica impele al propio aprendiente a imaginar estrategias emocionales y cognitivas que son procreadoras de experiencias de aprendizaje novedosas y creativas. Sin embargo, para que nuestra imaginación sacuda nuestra atención es vital el cultivo de la curiosidad.

Vida, aprendizaje y conocimiento, hemos visto líneas arriba, son unidad en la totalidad. No hay vida sin aprendizaje para conocer, como tampoco hay conocimiento sin aprender para vivir. El aprender conlleva a la búsqueda de respuesta ante el estímulo sensorial percibido que pone en movimiento nuestra emocionalidad para, acto inmediato, explorar cognitivamente aquello que atrajo nuestra atención, procesar la información relevante y procrear aprendizaje. Empero, para ir más allá en el conocer es necesario saber aprender en el aprender. Esto es, aprender a indagar para encontrar las respuestas a nuestras inquietudes y desarrollar el ser, accionar en el que la curiosidad es ingrediente intrínseco de la tendencia innata que nos impulsa a conocer en la autonomía de nuestro yo.

Saber sobre algo que se requiere conocer, que interesa por alguna razón o atrae nuestra atención y nos motiva, conlleva una carga emocional que emerge de la curiosidad movilizadora de nuestra atención cognitiva, lo que alienta a indagar sobre aquello que se pretende y quiere conocer. Actitud que impulsada con sentido pedagógico alienta a inquirir para averiguar sobre lo que se indaga. La acción de investigar sobre aquello que motivó nuestra atención tiene preeminencia en el aprender, ya que implica procedimientos relacionales que conllevan a ubicar, identificar, comparar y relacionar información relevante vinculada al asunto constitutivo de aquello que se quiere saber. Al conocerlo y explicarlo adquirimos nuevo conocimiento y aprendemos en el aprender.

Proceder que está en la base del sentido común y en el germinar del método científico. La llaneza procedimental es de profunda belleza mediadora del aprendizaje, sobre todo cuando éste ocurre en la autonomía de la persona porque es propicia a situaciones favorables que potencia las habilidades intelectuales, operativas y percep- 
tivas. Habilidades que estimulan la creatividad porque tras ella se suceden cambios cognitivos que modifican el patrón de observación, comportamiento y actitudes que pueden significar un salto en las condiciones existenciales de nuestro vivir.

Este proceder abre la mente hacia la consciencia que tiene el desaprender para reaprender y aprender algo nuevo o distinto, acción germinal de nuevas redes neuronales que facilitan continuar con un aprendizaje de por vida y para la vida. El reto consiste en movilizar la curiosidad de la persona para que en el hacer investigativo sitúe el aprendizaje en el aprender propiciador de conocimiento y sepa comunicar lo aprendido con estilo comprensible a través de la escritura, acto de reflexión que implica la autoevaluación del propio proceso de aprendizaje.

\section{COLOFÓN: CAMINO EN EL APRENDER}

Aprender en el aprender implica la interrelación de senderos emociónaley racionales que recorre el aprendiente en la autonomía de su propio ritmo de aprendizaje, cuando la inquietud cognitiva moviliza su atención. La dialógica indagatoria se pone en acción al momento en que nuestra percepción capta y explora una idea generadora, busca una explicación profunda de un tema de interés o el estudio de un problema que es necesario resolver. Preámbulo cognitivo que conduce a plantear preguntas significativas que permiten identificar qué información relacionada es la que debo buscar, ordenar para comparar, relacionar para establecer conexiones y arribar a un conocimiento de aquello que es de mi interés o necesidad de aprender. Paso a paso debo ir revisando el camino andado para autoevaluar mi estrategia de búsqueda, los logros que voy obteniendo, los posibles errores en que pudiera incurrir y aprender de ellos, conocer cómo es qué he aprendido y cómo puedo continuar aprendiendo en ese aprender.

El germinar cognitivo es continuo camino por recorrer a lo largo de la vida. Como aprendiente el emocionar imprime mi huella intelectual al actuar para conocer. Camino intelectual que se hace en el permanente aprender y reaprender, y cuando vuelvo la vista para evaluar los pasos de la búsqueda en mi aprender, sé más sobre lo aprendido y cómo he recorrido ese hacer que me condujo a conocer, recursividad que me sitúa en el permanente camino de conocer, desplegar mis habilidades y ubicar mis aptitudes con actitud prospectiva. 
Aprender en el aprender nos hace comprender que el aprendizaje es gozo y no obligatoriedad impuesta, que el esfuerzo intelectual conduce al germinar del saber y nos muestra la importancia de la autoorganización en la autonomía de nuestra dimensión personal, nos descubre que aprender es crear condiciones para seguir aprendiendo a lo largo de la vida, mantener el sentido crítico y la reflexión sin abandonar la dimensión emocional. Relaciones sustantivas que abonan el campo de cultivo humanista y ético tan necesario fortalecer para afrontar los retos de la SC.

\section{REFERENCIAS}

Assmann, H. (2002). Placer y ternura en la educación. Hacia una sociedad aprendiente. Madrid: Narcea.

Bauman, Z. (2007). Tiempos líquidos. Vivir en una época de incertidumbre. Barcelona: TusQuets Editores.

Blakemore, S.-J. y Frith, U. (2007). Cómo aprende el cerebro. Las claves para la educación. Barcelona: Ariel.

CCE (2001). Comunicación de la Comisión. Hacer realidad un espacio europeo del aprendizaje permanente. COM 678 final. Bruselas: Comisión de las Comunidades Europeas.

Carr, N. (2013). ¿Qué está haciendo internet con nuestras mentes? México: Taurus.

Damasio, A. (2013). El error de Descartes. La emoción, la razón y el cerebro humano. Barcelona: Booket Ciencia.

David, P. A. y Foray, D. (2002). "Fundamentos económicos del sociedad del conocimiento", Comercio Exterior, 52(6), junio, pp. 472-489.

Delgado, A. (2009). "Redes, el principio vital”, en Karin Ohlenschäger y Luis Rico (Dirección), Banquete: nodos y redes. España: Sociedad Estatal para la Acción Cultural Exterior, pp. 79-84.

Echeverría, R. (2012). Escritos sobre aprendizaje: recopilación. Argentina: J. C. Sáez editor.

Harari, Y. N. (2014). De animales a dioses. Breve historia de la humanidad. México: Debate.

Jensen, E. (2004). Cerebro y aprendizaje. Competencias e implicaciones educativas. Madrid: Narcea.

Konnikova, M. (2014). ¿Cómo pensar como Sherlock Holmes? México: Paidós.

Lipovetsky, G. y Serroy, J. (2010). La cultura-mundo. Respuestas a una sociedad desorientada. Barcelona: Anagrama.

López de Maturana, S. (2010). Maestros en el territorio. La Serena: Universidad de La Serena. 
Lucinnovation (2008). "Gestión des connaissances savoir implicite et explicite", Lucinnovation: Luxembourg. <www.innovation. public.lu/fr/innover/gestionconnaissances-fr. $\underline{\mathrm{pdf}}>$.

Luhmann, N. (1998). Sistemas sociales. Lineamientos para una teoría general.Barcelona: Anthropos-Universidad Iberoamericana-Centro Editorial Javerino.

Luisi, P. L. (2010). La vida emergente. De los orígenes químicos a la biología sintética. Barcelona: TusQuets.

Marcelo, C. (2001). "Aprender a enseñar para la Sociedad del Conocimiento", en Revista Complutense de Educación, 12(2), pp. 531-593. Universidad Complutense de Madrid.

Margulis, L. y Sagan, D. (1996). ¿Qué es la vida? Barcelona: Metatemas.

Maturana Romesín, H. (2004). Transformación en la convivencia. Chile: J. C. Sáez editor.

Maturana Romesín, H. y Varela, F. (2003). El árbol del conocimiento. Las bases biológicas del entendimiento humano. Argentina: Lumen Editorial Universitaria.

Mora, F. (2008). El reloj de la sabiduría. Tiempos y espacios en el cerebro humano. Madrid: Alianza Editorial.

Mora, F. (2013). Neuroeducación. Solo se puede aprender aquello que se ama. Madrid: Alianza editorial.

OCDE-CERI. (2004). La comprensión del cerebro. El nacimiento de una ciencia del aprendizaje. Santiago de Chile: Ediciones Universidad Católica Silva Henríquez.

Ohlenschläger, K. (2009). "Nodosy redes", en María López Diez (Dirección editorial), Banquete. Nodos y redes. Barcelona: Sociedad Estatal para la Acción Cultural Exterior de España-Gobierno de España-Centro de Arte y Creación Industrial, pp. 19-30.

Puebla Wuth, R. S. (2009). Las Funciones cerebrales del aprendiendo a aprender (Una aproximación al sustrato neurofuncional de la Metacognición). Revista Iberoamericana de Educación, 50(3), 1-10. Recuperado a partir de https:// rieoei.org/RIE/article/view/1865.

Skolimowski, H. (2016). La mente participativa. España: Atalanta.

Stiglitz, J. y Greenwald, B. (2015). La creación de una sociedad del aprendizaje. Un nuevo enfoque hacia el crecimiento, el desarrollo y el progreso social. México: Crítica.

Velasco Toro, J. M. (2015). "Investigación educativa: aprender a indagar para aprender a crear", en Francisco Santillán Campos, Tendencias en el desarrollo y aplicación de la investigación educativa de México. México: CENID Editorial, pp. 59-73.

Velasco Toro, J. M., Peredo Carmona, P. B., Fuentes Navarro, F., González Cajica, M.G. y López Callejas, M. (2016). Horizonte educativo. Hacia una Pedagogía de la autoorganización. México: Universidad Pedagógica Veracruzana. 
